Study of the mechanical behavior of masonry repair lime-based mortars cured and exposed under different conditions

\author{
J. Lanas ${ }^{a}$, R. Sirera ${ }^{b}$, J.I. Alvarez ${ }^{b, *}$ \\ ${ }^{\text {a }}$ Laboratorio de Edificación, University of Navarra, 31080 Pamplona, Spain \\ ${ }^{\mathrm{b}}$ Departamento de Química, University of Navarra, 31080 Pamplona, Spain
}

$\mathbf{N}^{\circ}$ of pages: 15

$\mathbf{N}^{0}$ of tables: 8

$\mathbf{N}^{\mathbf{0}}$ of figures: 12

Keywords: C. Durability; C. Cycles; C. Compressive Strength; B. SEM; E. Mortar.

Please, send all correspondence to:

Dr. José I. Alvarez Galindo

Dpto. de Química

Fac. de Ciencias

Universidad de Navarra

$\mathrm{C} /$ Irunlarrea $\mathrm{s} / \mathrm{n}$

31.080 Pamplona (Navarra)

Spain

Phone: 34948425600

Fax: 34948425649

E-mail: jalvarez@unav.es 


\title{
Study of the mechanical behavior of masonry repair lime-based mortars cured and
} exposed under different conditions

\author{
J. Lanas ${ }^{a}$, R. Sirera ${ }^{b}$, J.I. Alvarez ${ }^{b, *}$ \\ a Laboratorio de Edificación, University of Navarra, 31080 Pamplona, Spain \\ ${ }^{\mathrm{b}}$ Departamento de Química, University of Navarra, 31080 Pamplona, Spain
}

\begin{abstract}
Specimens of aerial and hydraulic lime-based mortars to be used in restoration works were prepared, hardened and subjected to different environments in order to study their mechanical behavior and durability. Outside exposure, weathering cycles in a climatic chamber, $\mathrm{SO}_{2}$-rich environment, freezing-thawing cycles and indoor exposure were selected to expose (as control group) the mortars.
\end{abstract}

Flexural and compression strength tests were performed at 7, 14, 21 and 28 days. Porosity values and SEM-EDAX analysis were used to evaluate the microstructural changes.

Flexural strength has been strongly influenced by the RH of the environments. Outside exposure improves, in general, the compressive strength, whereas $\mathrm{SO}_{2}$-chamber only provides the strength in hydraulic specimens. Porosity reduction has been related with a strength increment.

In climatic chamber, the porosity increment matches a gradual higher degree of alteration. A strength reduction has been determined through a fracture mechanism using the cracks of climatic alteration. In $\mathrm{SO}_{2}$-chamber, sulfation appears as a surface phenomenon, giving gypsum in aerial specimens and gypsum and syngenite in hydraulic specimens, as SEM/EDAX confirms. Freezing-thawing cycles showed a high destruction capacity. Hydraulic specimens endured better durability tests than aerial specimens: a discussion on the mortar durability was also introduced.

Keywords: C. Durability; C. Cycles; C. Compressive Strength; B. SEM; E. Mortar. 


\section{Introduction}

The use of similar materials in restoration projects of Cultural Heritage has been clearly stated [1,2]. Advantages of lime-based mortars in these works have been noticed [3,4]. In a previous research, mechanical behavior of masonry repair mortars has been studied: aerial lime and hydraulic lime-based mortars, respectively [5,6]. In a recent paper, compositional changes of repair lime-based mortars exposed to different environments have been evaluated [7].

However, the knowledge about the durability of these mortars is a critical aspect of their properties. By exposing mortar samples at different environmental conditions, different aspects of this durability were considered: outside exposure (urban atmosphere) [8], $\mathrm{SO}_{2}$ pollutant exposure [9-12], weathering cycles (in a climatic chamber) [13,14] or freezing-thawing cycles $[15,16]$.

Damage to mortars from freezing and thawing has been reported owing to the expansion of pore water during freezing [15]. This way of alteration must be also taken into account in outside exposure and artificial weathering. The occurrence of the cracks (length of fissuration), weight loss, porosity changes, ultrasonic pulse velocity and color variations have been used to evaluate the durability in different building materials [15-17].

From the previous works about the $\mathrm{SO}_{2}$ and other pollutants deposition, it was unquestionably achieved enough knowledge about the chemical reactions [10], the catalysts in $\mathrm{SO}_{2}$ oxidation [11,18], the sulfite and sulfate quantification [19] and the black crusts formed by deposition of environmental pollution [20]. However, these facts could have mechanical repercussions, for example: a $\mathrm{SO}_{2}$-rich environment causes the formation of gypsum $\left(\mathrm{CaSO}_{4} \cdot 2 \mathrm{H}_{2} \mathrm{O}\right)$ on the external layer of the mortar surface [8,11]. In hydraulic binders the effects of sulfation can be even more serious: ettringite $\left(3 \mathrm{CaO} \cdot \mathrm{Al}_{2} \mathrm{O}_{3} \cdot 3 \mathrm{CaSO}_{4} \cdot 32 \mathrm{H}_{2} \mathrm{O}\right)$ and also thaumasite $\left(\mathrm{CaSiO}_{3} \cdot \mathrm{CaSO}_{4} \cdot \mathrm{CaCO}_{3} \cdot 15 \mathrm{H}_{2} \mathrm{O}\right)$ can be formed as a result of the reaction between the calcium aluminates and silicates of the mortar and the gypsum produced by the sulfation process $[18,21,22]$. 
The formation of ettringite gives rise to cracks due to the expansive nature of the reaction which takes place [23], whereas during the formation of thaumasite a severe damage of the binder matrix can be checked owing to the attack on the calcium silicate hydrates [18,21].

Owing to the proved influence of the environmental conditions on the mechanical properties, the aim of this paper is to study in a systematic way the variation of the mechanical behavior in hardened repair lime-based mortars (aerial and hydraulic) subjected to different environments: outside exposure, weathering cycles (in a climatic chamber), $\mathrm{SO}_{2}$-rich environment (in a $\mathrm{SO}_{2}$ chamber), freezing-thawing cycles and indoor exposure (laboratory conditions). This work allows to evaluate and compare the durability of the repair lime-based mortars. Microstructure of the mortars has been also studied in order to relate their mechanical behavior and their durability.

\section{Experimental work}

\subsection{Mortars}

Two different kinds of limes have been used to prepare the mortars: aerial lime and natural hydraulic lime. The first one is a commercial-hydrated lime powder of the class CL90 according to the European normative [24] and was supplied by Calinsa S.A. (Navarra). The second one is a commercial lime of the class HL5 [24], and it was provided by Chaux Bruyeres (Saint-Frontsur-Lémance, Fumel). Table 1 gives their chemical characterization (according to European Standard) [25] and Fig. 1 shows their X-ray diffractograms.

In this work, a pure limestone aggregate of angular edges with controlled granulometry was used. It was supplied by CTH Navarra (Navarra). Its chemical composition, X-ray diffractogram and grain size distribution are introduced in Table 1, Fig.1 and Fig. 2, respectively.

The binder:aggregate ratio prepared is summarized in Table 2. Weight proportions were used to avoid measurement imprecision on mixing process. The equivalence with volume proportion is (1:1). This B/Ag (binder/aggregate) ratio was chosen due to the best mechanical behavior of this proportion, in both kind of limes, among ratios ranging from (1:1) to (1:5), as stated in previous works $[5,6]$. 
The water:lime (W:L) ratio used to prepare all mortar pastes was (1:2). A normal consistency and a good workability (165 mm and $170 \mathrm{~mm}$ for aerial and hydraulic lime mortars, respectively, measured by the flow table test [26]) were achieved by using this amount of water. The mixer used was a Proeti ETI 26.0072 [27]. Water and lime were blended for 5 min. Aggregate was then added and mixed for 5 min in low speed, and finally for 1 min in high speed. The mortars were molded in prismatic 40x40x160 mm casts [28] using a ICON automatic jolting table to compact them and to remove any air bubbles and voids [27]. Mortars were prepared by groups of 35 samples (each day 35 samples were obtained). During 4 days they remained in the molds under room laboratory conditions (RH $60 \pm 10 \%$ and $20 \pm 5^{\circ} \mathrm{C}$ ). After this period, the samples were demolded, weighted and cured during 24 more days in the same laboratory conditions. During this process, samples were located on a metallic plane grating, lain on a 40x160 mm face.Therefore, prepared mortars were hardened 28 days previously to carry out the different tests.

\subsection{Environments of exposure}

After 28 days of their manufacture in laboratory conditions, mortars were placed in different conditions:

(i) outside exposure (this test was made in autumn, with temperatures between 5 and $15^{\circ} \mathrm{C}$, with several rainy days, and RH ranging between 70-90\%);

(ii) in a climatic chamber CCI FCH-XENOLAB 1500: climatic cycles of 24 hours with different conditions of relative humidity $(\mathrm{RH})$, temperature $(\mathrm{T})$, ultraviolet light and rain were carried out. This regime tries to simulate extreme and intermediate atmospheric conditions, with high, low and intermediate temperatures, and with rain cycles. These stages should show, approximately, the conditions suffered by a mortar for a year, condensed in a few days. Table 3 summarizes the steps of the climatic cycles.

(iii) in a $\mathrm{SO}_{2}$ chamber $[29,30]$ where were performed cycles of 24 hours according to SFW

2,0S DIN 50018 [30] (Table 4);

(iv) in a freezer to determinate their resistance to freezing and thawing (Table 5); 
(v) under room laboratory conditions (RH $60 \pm 10 \%$ and $20 \pm 5^{\circ} \mathrm{C}$ ), as a control group.

105 specimens were prepared for each mortar type, i.e. a total of 210 specimens have been studied together. By using the techniques described below, tests and analyses were performed after exposing times of 7, 14, 21 and 28 days. The reported results were an average value of the three similar specimens, and the variation coefficients were below $15 \%$ in compressive strength results.

\subsection{Mechanical evaluation}

The three-point flexural test was performed on the mortar samples using a Frank/Controls 81565 compression machine at low rates of loading $(4 \mathrm{~mm} / \mathrm{min})$. The device of flexural strength determination was an Ibertest IB 32-112V01.

Compression strength test was carried out on the two fragments of each specimen resulting of the previous flexural test. The rate of loading was $10 \mathrm{~mm} / \mathrm{min}$, and the device of compression strength determination was a Proeti ETI 26.0052.

\subsection{Microstructural analysis}

The pore structure was evaluated at the test days through open porosity measurements, in order to determine the porosity changes in the different conditions. The total porosity is expressed as $\mathrm{P}$, in percent, and is determined according to the water saturation test [31] with a hydrostatic balance.

A Digital Scanning Microscope Philips XL 30CP coupled to a EDS/EDAX Phoenix was used to view the mortars and to carry out microanalysis determinations.

\section{Results and discussion}

\subsection{Mechanical evaluation}


Compression and flexural strength values of the mortars exposed to different environments are summarized in Fig. 3. Aerial mortar samples subjected to climatic chamber have not withstood cycles after 7 test days; therefore, their mechanical evaluation could not be carried out, and they have been considered in the next section (Durability tests).

Flexural strength has been strongly influenced by the RH and the amount of free water into the mortar. As results show, aerial lime-based mortars subjected to outside exposure have erratic values of flexural strength, as a function of the weather at the test day, which governs the RH. The drying process may have some influence on these flexural tensile strength values. If drying is not uniform, the different sides of the specimen would display different microcracking, explaining these erratic values [32,33]. In this work, samples cured previously to their exposure at different environments show the same external appearance, without visible cracks.

Similar behavior can be observed for indoor exposure. It is necessary to consider that 28 test days could be a short time to achieve a stabilization of the flexural strength in aerial mortars [5]. Large weight changes can be observed for outside exposure, $\mathrm{SO}_{2}$-chamber and climatic chamber until 28 exposure days [7]. Therefore, the specimens could be still in transitory conditions regarding their flexural strength. These results are confirmed by the carbonation degree evaluation, which is also reported in the cited work [7]: carbonation has not finished at the test times $[5,6]$. In $\mathrm{SO}_{2}$-chamber exposure, flexural strength increases due to a high $\mathrm{RH}$ in the environment.

Compressive strength shows a more systematic behavior than flexural strength. Outside exposure causes a strength reduction at 7 test days, followed by an increase, as expected.

Indoor exposure, no subjected to the weather, improves slightly the strength. Aerial mortars require longer time to exhibit outstanding strength increments [5].

A strength reduction has been tested for specimens exposed to $\mathrm{SO}_{2}$-chamber. The gypsum formation due to the sulfation phenomenon, as proved in a previous work [7], causes the reduction of compressive strength.

Hydraulic specimens show similar behavior of the flexural strength than aerial mortars. $\mathrm{RH}$ appears to have a great influence on these values: $\mathrm{SO}_{2}$-chamber exposure improves the flexural 
strength owing to the high RH. Outside exposure enhances flexural strength as a function of the weather: high RH allows to increase the strength at different test days.

An outstanding increment in the compressive strength can be checked after 28 test days in hydraulic specimens subjected to outside exposure and $\mathrm{SO}_{2}$-chamber: rising the amount of free water, these environments enhances the $\mathrm{CSH}$ formation as well as the carbonation reaction, improving the compressive strength.

Weathering deterioration due to the outside exposure and sulfation phenomenon has not a clear influence on the compressive strength in hydraulic mortars. Probably, at the test days, the strength increment due to the hydration and carbonation processes surpasses its reduction owing to the alteration phenomena. A further study on $\mathrm{SO}_{2}$ dry exposure will be necessary to evaluate the behavior of hydraulic specimens.

As it was already mentioned, indoor exposure (with a small amount of free water) does not change the strength.

In climatic chamber, both flexural and compressive strengths show a reduction. The mechanism of the fracture during strength determination in specimens subjected to climatic chamber is very different to the other environments. In climatic chamber exposure, the cracks generated into the specimen have been used to break it, whereas the other environments show an uniform mechanism of the fracture, as Fig. 4 presents.

\subsection{Durability tests}

Durability of repair lime-based mortars has a great interest if it is considered their use in restoration works. Durability of the mortars can be discussed through the different environments of the exposure.

In this section the discussion has been focused on the weathering cycles (climatic chamber), freezing-thawing cycles and $\mathrm{SO}_{2}$-chamber.

Table 6 summarizes a qualitative evaluation of the alteration degree in specimens subjected to the climatic chamber. Aerial lime-based mortars are totally destroyed at 7 test days. However, none hydraulic mortar reaches the degree 5 of alteration after 28 test days. 
Weathering conditions (climatic chamber) proposed in the experimental design were excessively extreme for aerial lime-based specimens. As it will be discussed in next section, a higher porosity of these mortars causes a higher degree of deterioration by water movement (freezing-thawing cycles, rain cycles, dry conditions...). Table 7 shows the evaluation of the alteration degree of specimens under freezing and thawing cycles, using the same criterion that in evaluation of weathering cycles.

With only three F-T cycles $100 \%$ of aerial specimens are destroyed, whereas after 11 F-T cycles any hydraulic specimens does not reach the degree 5 of alteration.

As it has been proved, F-T cycles show a higher destruction capacity on lime-based mortars than the climatic cycles designed in this work.

Aerial specimens reached a 100\% of destruction after 3 cycles in F-T exposure, whereas this 100\% was obtained after 7 cycles (7 test days) in climatic chamber exposure. Hydraulic specimens show a $55.6 \%$ of specimens with a degree 4 after 11 F-T cycles, and a $33.3 \%$ in degree 4 after 28 climatic cycles (28 test days, Figs. 5 and 6 respectively).

Nevertheless, F-T exposure gives others intermediate degrees of alteration (degree 1 to 4 in hydraulic mortars), whereas climatic chamber alters the specimens in a similar way (in hydraulic mortars, at 21 test days only degrees 2 an 3, and at 28 test days only degrees 3 and 4 were obtained).

From this fact, it can be inferred that in weathering test (climatic chamber) there are others alteration factors for lime-based mortars, apart from freezing-thawing phenomenon.

Mechanical strength can be related to durability of the mortar: specimens with higher strength (hydraulic mortars) show higher durability. This fact is linked to the porosity of the mortars, as it will be discussed in the next section.

The degree of alteration in climatic chamber causes a strength reduction, enhancing the mechanism of the fracture through the cracks induced by weathering exposure, as discussed in section 3.1. 
$\mathrm{SO}_{2}$-rich environment causes an alteration on the external layer of the specimens, as it has been proved by the previous analyses. Fig. 7 shows the $\mathrm{SO}_{2}$ alteration in hydraulic specimen with white deposits on the surface of the mortar.

\subsection{Microstructural analysis}

\subsubsection{Porosity determination}

Table 8 shows the porosity values at different exposures versus test days. The higher porosity of aerial specimens is related to their lower strength compared to hydraulic specimens [6].

In hydraulic mortars, outside and $\mathrm{SO}_{2}$-chamber exposures cause reduction of porosity which improves the compressive strength, as discussed in section 3.1, due to the amount of free water in these environments.

In indoor exposure, porosity values were kept constant, so the compressive strength does not change.

In durability tests, the porosity increment agrees with a gradual higher degree of alteration: this fact is related to: a) mainly, with the water movement inside the pores and its expansion when freezes; b) the easy access of the pollutants into the mortar. $\mathrm{CO}_{2}(\mathrm{~g})$ can penetrate easier into the mortar, and these facts justify the increment of the carbonation and also the higher alteration degree (with a strength drop, as discussed in section 3.1).

\subsubsection{SEM analyses}

The microstructure of the exposed mortars was analyzed by SEM/EDS. For outside and indoor exposures, calcite crystals were observed at the mortar surface.

In $\mathrm{SO}_{2}$-rich environment, prismatic and plate-like crystals of the gypsum were detected in aerial lime-based mortars. The whole mortar surface appears covered of gypsum, in agreement with previous works studying the $\mathrm{SO}_{2}$ deposition [11], giving an idea about the aggressive conditions of the attack due to the higher relative humidity and the temperature (Fig. 8). 
In hydraulic specimens, $\mathrm{SO}_{2}$-chamber exposure gives different alteration areas (Fig. 9). As Fig. 10(a) shows, large prismatic crystals similar to those in the aerial mortar have been checked. Analysis by EDS (Fig. 10(b)) indicated the presence of S, O and Ca, confirming gypsum $\left(\mathrm{CaSO}_{4} \cdot 2 \mathrm{H}_{2} \mathrm{O}\right)$ formation.

Prismatic needle-shaped crystals at low magnifications (at the bottom of Fig. 9) smaller than the previously mentioned have been observed (Fig. 11(a)). In the previous work, by XRD, FTIR and TG-DTA the presence of syngenite $\left(\mathrm{K}_{2} \mathrm{Ca}\left(\mathrm{SO}_{4}\right)_{2} \cdot 2 \mathrm{H}_{2} \mathrm{O}\right)$ in hydraulic mortars exposed to $\mathrm{SO}_{2}$-chamber has been proved [7]. In dry conditions, the $\mathrm{SO}_{2}$ attack gives potassium sulfate, because it has a high solubility $(120 \mathrm{~g} / \mathrm{L})$. This $\mathrm{K}_{2} \mathrm{SO}_{4}$ is a kinetic product, but it has not been determined in the present wet $\mathrm{SO}_{2}$ attack conditions: syngenite was formed in this more aggressive environment owing to its lower solubility (2.5 g/L) [11]. It is a thermodynamic control product of the deterioration by $\mathrm{SO}_{2}$, as well as gypsum (solubility $2.4 \mathrm{~g} / \mathrm{L}$ ). In aerial mortars, no syngenite is detected due to the lower amount of potassium in this lime, as shows the chemical analysis (Table 1). In agreement with the cited previous study [7], the presence of S, K and Ca has been determined by EDS analysis (Fig. 11(b)), confirming syngenite formation in these areas.

The CSH gel is similar to that observed in previous works [6,11]. Morphology for CSH gel (tobermorite gel) corresponds to type I-like needles (Fig. 12(a)) [11]. EDS analysis shows the main presence of gypsum crystals, as well as a little amount of Si and Al, which could correspond to CSH gel (Fig. 12(b)). It can be concluded that the product of the hydration of the hydraulic compounds has not been influenced by the presence of $\mathrm{SO}_{2}$.

\section{Conclusions}

(1) Flexural strength has been strongly influenced by the RH of the environments of the exposure. Outside exposure causes, in general, an increase of the compression strength due to the higher RH degree, both in aerial and in hydraulic specimens (higher carbonation and hydration of $\mathrm{CSH}$ ). $\mathrm{SO}_{2}$-chamber exposure gives different behavior: in aerial mortars, gypsum 
formation causes a strength drop, whereas an outstanding strength increment has been observed in hydraulic mortars at the test days.

Indoor exposure does not change the compressive strength at the test days: lime-based mortars require longer time to improve their strength in laboratory conditions.

(2) Mechanical behavior and durability have been related to the porous structure at different environments. In aerial mortars, outside and $\mathrm{SO}_{2}$ exposures give an increase of porosity, causing a strength decreases and higher alteration degrees. In hydraulic mortars, the reduction of porosity improves the compressive strength in these environments.

Porosity values were kept constant in indoor exposure, so the compressive strength does not show any change.

(3) In climatic chamber, strength is reduced. The cracks generated into the specimens facilitate their breaking during the mechanical evaluation.

(4) SEM/EDS analysis confirms the process of sulfation on mortar surfaces. Macroscopic white deposits in hydraulic specimens subjected to $\mathrm{SO}_{2}$-chamber match gypsum and syngenite areas. Morphology for CSH gel corresponds to type I-like needles in all the exposures: the hydration of the hydraulic compounds has not been influenced by them.

\section{Acknowledgements}

The present study was supported by the Spanish Ministerio de Ciencia y Tecnología, Plan Nacional de Investigación, Desarrollo e Innovación Tecnológica (I+D+I) program, Project MAT 2000-1347.

The authors would like to thank José María Galech (CTH, Navarra), Fernando Moreno (Calinsa S.A., Navarra) and Chaux Bruyeres for the material supplied. We are also grateful to Dr. Jordana and Dr. Jon Joseba Echeberría for their help with SEM. 


\section{References}

[1] Venice Charter, International Charter for the conservation and restoration of monuments and sites, Venice, 1964, (http://www.icomos.org/docs/venice_charter.html)

[2] Conclusions of the symposium "Mortars, cements and grouts used un conservation of historic buildings”, Rome, Mater. Struct. 23 (1990) 235.

[3] C. Rodríguez-Navarro, E. Hansen, W.S. Ginell, “Calcium hydroxide cristal evolution upon ageing of lime putty”, J. Am. Ceram. Soc. 81 (11) (1998) 3032-3134.

[4] A.W. Hendry, "Masonry walls: materials and construction”, Constr. Build. Mater. 15 (2001) 323-330.

[5] J. Lanas, J.I. Alvarez, "Masonry repair lime-based mortars: Factors affecting the mechanical behavior”, Cem. Concr. Res. 33 (2003) 1867-1876.

[6] J. Lanas, J.L. Perez Bernal, M.A. Bello, J.I. Alvarez, "Mechanical properties of natural hydraulic lime-based mortars”, Cem. Concr. Res. 34 (12) (2004) 2191-2201.

[7] J. Lanas, R. Sirera, J.I. Alvarez, “Compositional changes in lime-based mortars exposed to different environments”, Termochim. Acta 429 (2005) 219-226.

[8] G. Zappia, C. Sabbioni, C. Riontino, G. Gobbi, O. Favoni, “Exposure test of building materials in urban atmosphere” Sci. Total Environ. 224 (1998) 235-244.

[9] S. Martínez-Ramírez, A. Zamarad, G.E. Thompson, B. Moore, “Organic and inorganic concrete under $\mathrm{SO}_{2}$ pollutant exposure”, Build. Environ. 37 (2002) 933-937.

[10] M.T. Blanco-Valera, J. Aguilera, S. Martínez-Ramírez, F. Puertas, A. Palomo, C. Sabbioni, G. Zappia, C. Riontino, K. Van Balen, E.E. Toumbakari, “Thaumasite formation due to atmospheric $\mathrm{SO}_{2}$-hydraulic mortar interaction”, Cem. Concr. Comp. 25 (2003) 983-900.

[11] S. Martínez-Ramirez, “Influence of $\mathrm{SO}_{2}$ deposition on cement mortar hydration”, Cem. Concr. Res. 29 (1998) 107-111.

[12] C. Sabbioni, G. Zappia, C. Riontino, M.T. Blanco-Valera, J. Aguilera, F. Puertas, K. Van Balen, E.E. Toumbakari, “Atmospheric deterioration of ancient and modern hydraulic mortars”, Atmos. Environ. 35 (2001) 539-548. 
[13] E.A. Laycock, “Ten years of frost testing at Sheffield Hallam University”, Constr. Build. Mater. 16 (2002) 195-205.

[14] F. Boutin, P. Bromblet, "Evaluation of materials used in the replacement of sculptures in historical monuments”, Weathering of natural stone: causes, mechanism and measurement of stone damage, Proceedings of the 9th International Congress on Deterioration and Conservation of Stone, Venice, 2000, pp. 31-39.

[15] A.J. Klemm, P. Klemm, "The effects of the alternate freezing and thawing cycles on the pore structure of cementitious composites modified by MHEC and PVA”, Build. and Environ. 32 (6) (1997) 509-512.

[16] Y. Shao, C.J. Lynsdale, C.D. Lawrence, J.H. Sharp, “Deterioration of heat-cured mortars due to the combined effect of delayed ettringite formation and freeze/thaw cycles”, Cem. Concr. Res 27 (11) (1997) 1761-1771.

[17] R. Fort, M.C. López de Azcona, F. Mingarro, "Petrophysical analysis of the sculptures decay at the Cathedral of Burgos, Spain” Weathering of natural stone: causes, mechanism and measurement of stone damage, Proceedings of the 9th International Congress on Deterioration and Conservation of Stone, Venice, 2000, pp. 125-133.

[18] G. Zappia, C. Sabbioni, M.G. Pauri, G. Gobbi, “Mortar damage due to airborne sulfur compounds in a simulation chamber”, Mater. Struct. 27 (1994) 469-473.

[19] G. Gobbi, G. Zappia, C. Sabbioni, "Sulphite quantification on damaged stones and mortars”, Atmos. Environ. 32 (4) (1998) 783-789.

[20] C. Sabbioni, G. Zappia, N. Ghedini, G. Gobbi, O. Favoni, "Black crusts on ancient mortars”, Atmos. Environ. 32 (2) (1998) 215-223.

[21] M.E. Gaze, N.J. Crammong, “The formation of thaumasite in a cement:lime:sand mortar exposed to cold magnesium and potassium sulfate solutions”, Cem. Concr. Comp. 22 (2000) 209-222.

[22] R.P.J. van Hess, T.J. Wijffels, L.J.A.R. van der Klugt, “Thaumasite swelling in historic mortars: field observations and laboratory research”, Cem. Concr. Comp. 25 (2003) 1165-1171. 
[23] C. Sabbioni, A. Bonazza, G. Zappia, "Damage on hydraulic mortars: the Venice Arsenal”, Journal of Cultural Heritage 3 (2002) 83-88.

[24] EN 459-1, Building Lime. Part 1: Definition, specification and conformity criteria (2001).

[25] EN 196-2, Methods of testing cement. Part 2: Chemical Analysis of cement (1994).

[26] EN 1015-3, Methods of test mortar masonry. Part 3: Determination of consistence of fresh mortar (by flow table).

[27] EN 196-1, Methods of testing cement. Part 1: Determination of strength (1995).

[28] EN 1015-11, Methods of test for mortar masonry. Part 11: Determination of flexural and compressive strength of hardened mortar (1999).

[29] UNE-EN ISO 3231, Paints and varnishes. Determination of resistance to humid atmospheres containing sulfur dioxide.

[30] DIN Deutsches Insitut für Normung e.V., DIN 50018, Testing in Alternating Condensation Atmosphere Containing Sulphur Dioxide, May 1988

[31] RILEM, 1980. Recommended tests to measure the deterioration of stone and asses the effectiveness of treatment methods, Mater. Struct. 13 (1980) 175-253.

[32] J. Planas, M Elices, "Drying shrinkage effects on the modulus of rupture”, $5^{\text {th }}$ Int. RILEM Symposium, Barcelona, Eds. Z.P. Bazant and I. Carol, RILEM, E \& FN Spon, London (1993) pp. 357-368.

[33] M. Jirasek, Z.P. Bazant, Inelastic Analysis of Structures, J. Wiley \& Sons, New York, 2001. 


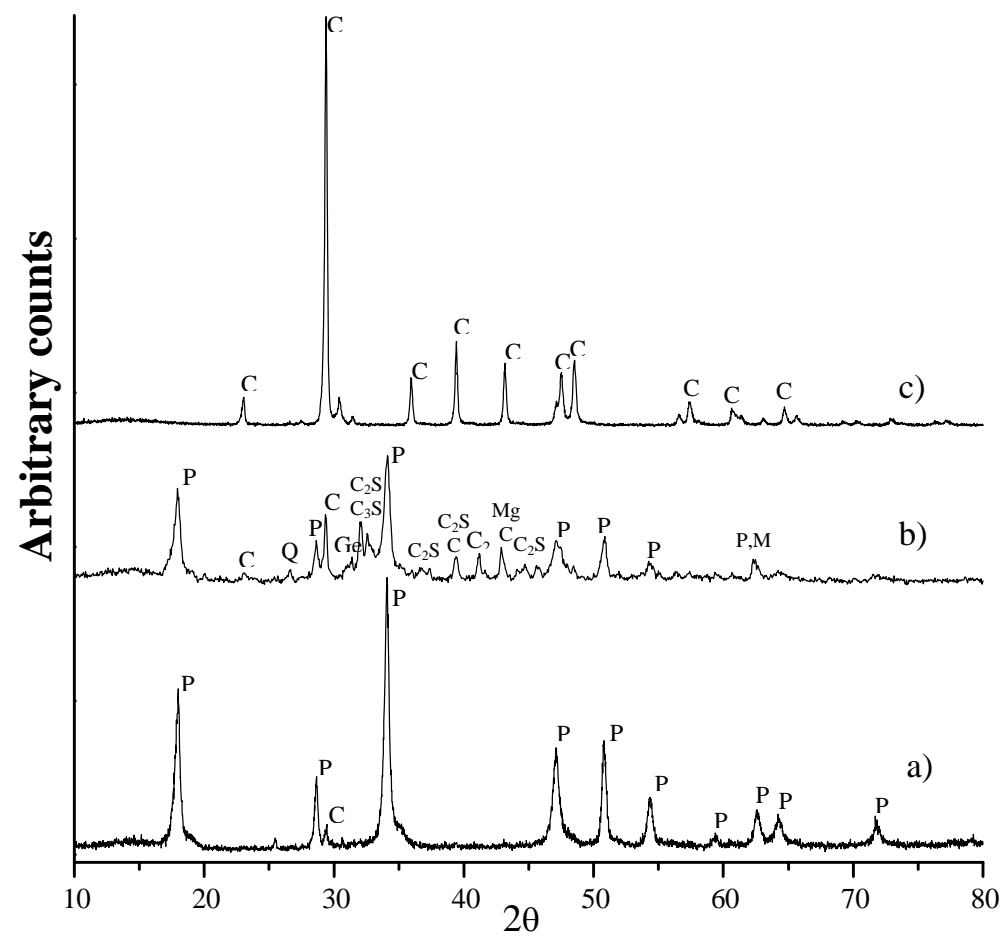

Fig. 1. XRD of: a) aerial lime; b) natural hydraulic lime; c) aggregate (C: Calcite (ICDD 05-0586); P: Portlandite (ICDD 44-1481); $\mathrm{C}_{2} \mathrm{~S}$ : Dicalcium silicate (ICDD 02-0843); $\mathrm{C}_{2} \mathrm{~S}$ : Tricalcium silicate (ICDD 02-0849); Mg: Periclase (ICDD 45-0946); Ge: Gehlenite, $\mathrm{C}_{2}$ AS: (ICDD 35-0755); Q: Quartz (ICDD 46-1045)).

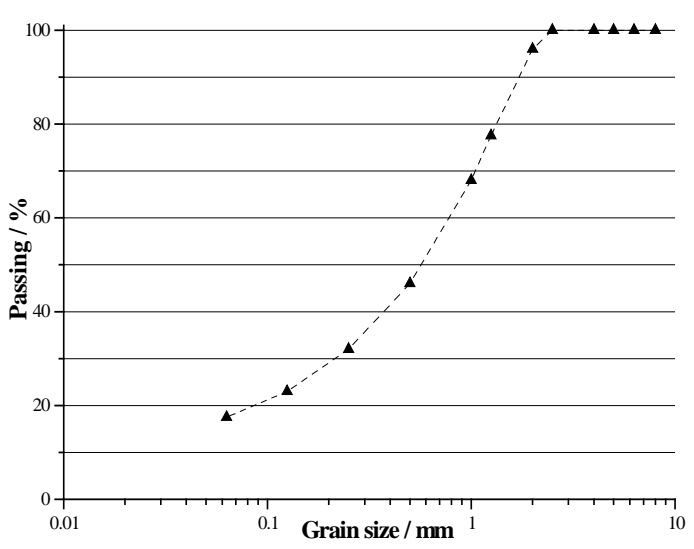

Fig. 2. Grain size distribution of the aggregate. 
Aerial lime-based mortars
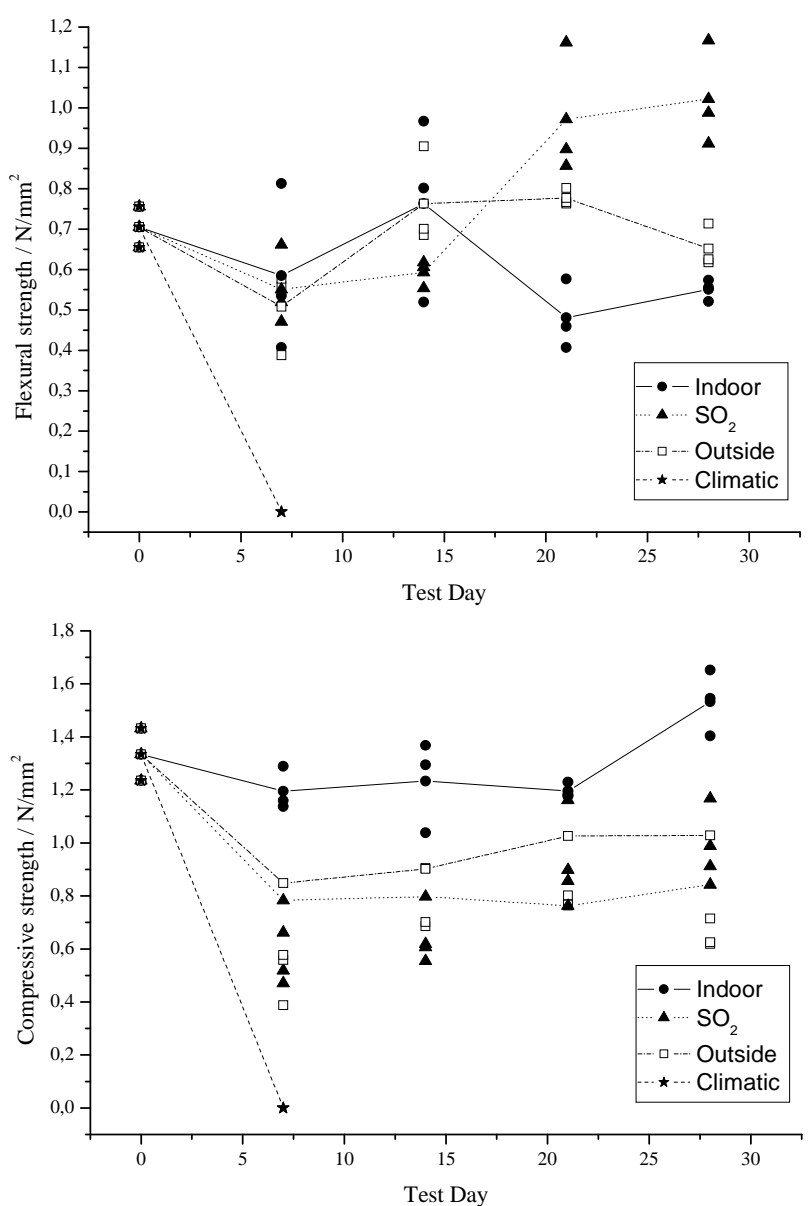

Hydraulic lime-based mortars
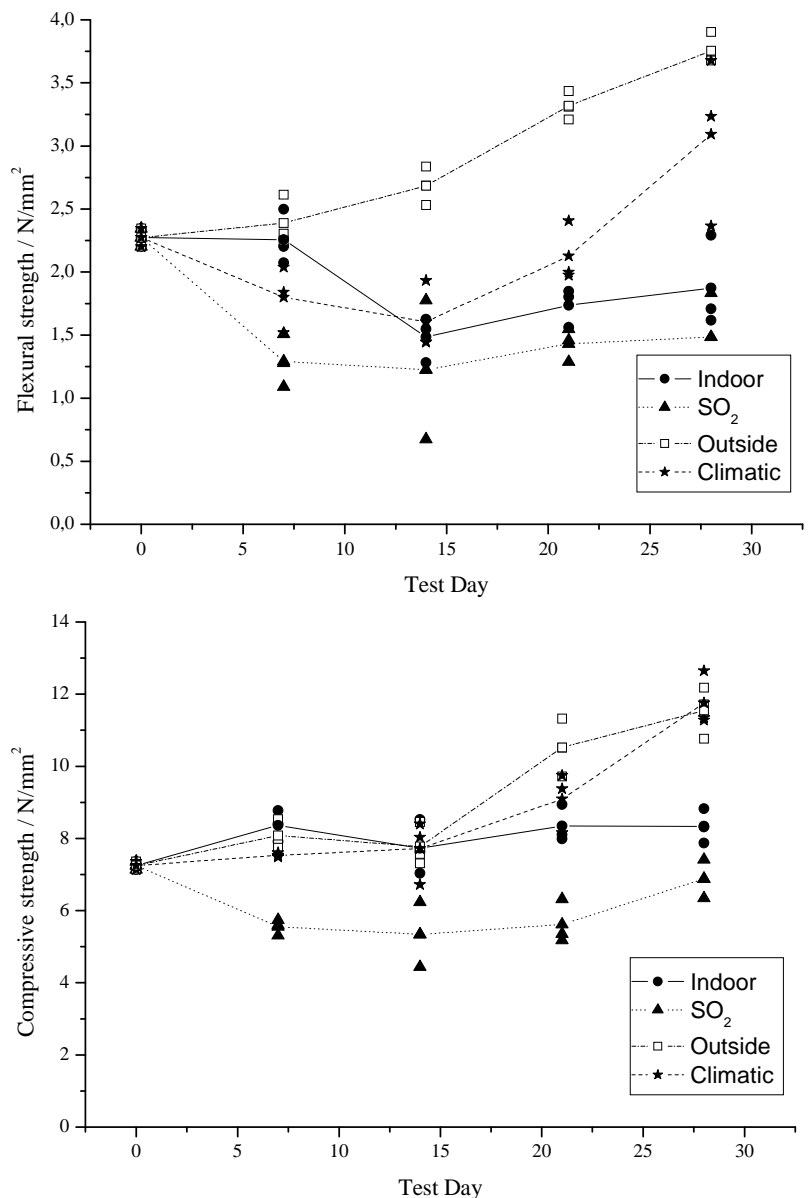

Fig. 3. Strength results in aerial and hydraulic lime-based mortars with different exposure conditions. All the measured points are shown, as well as the average line.

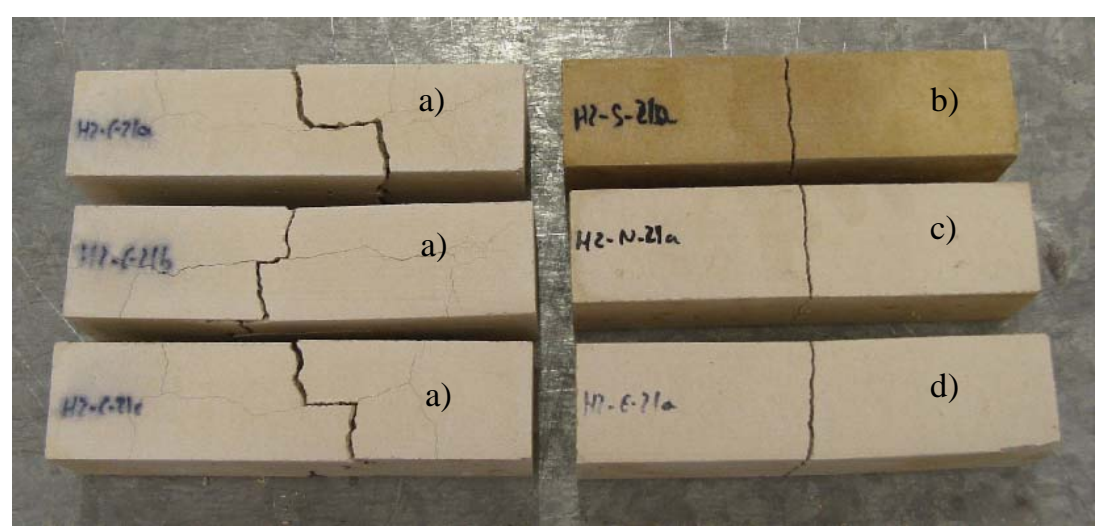

Fig. 4. Specimens after flexural determination subjected to all environments: a) specimens tested after climatic chamber exposure; b) $\mathrm{SO}_{2}$-chamber, c) indoor; d) outside. 

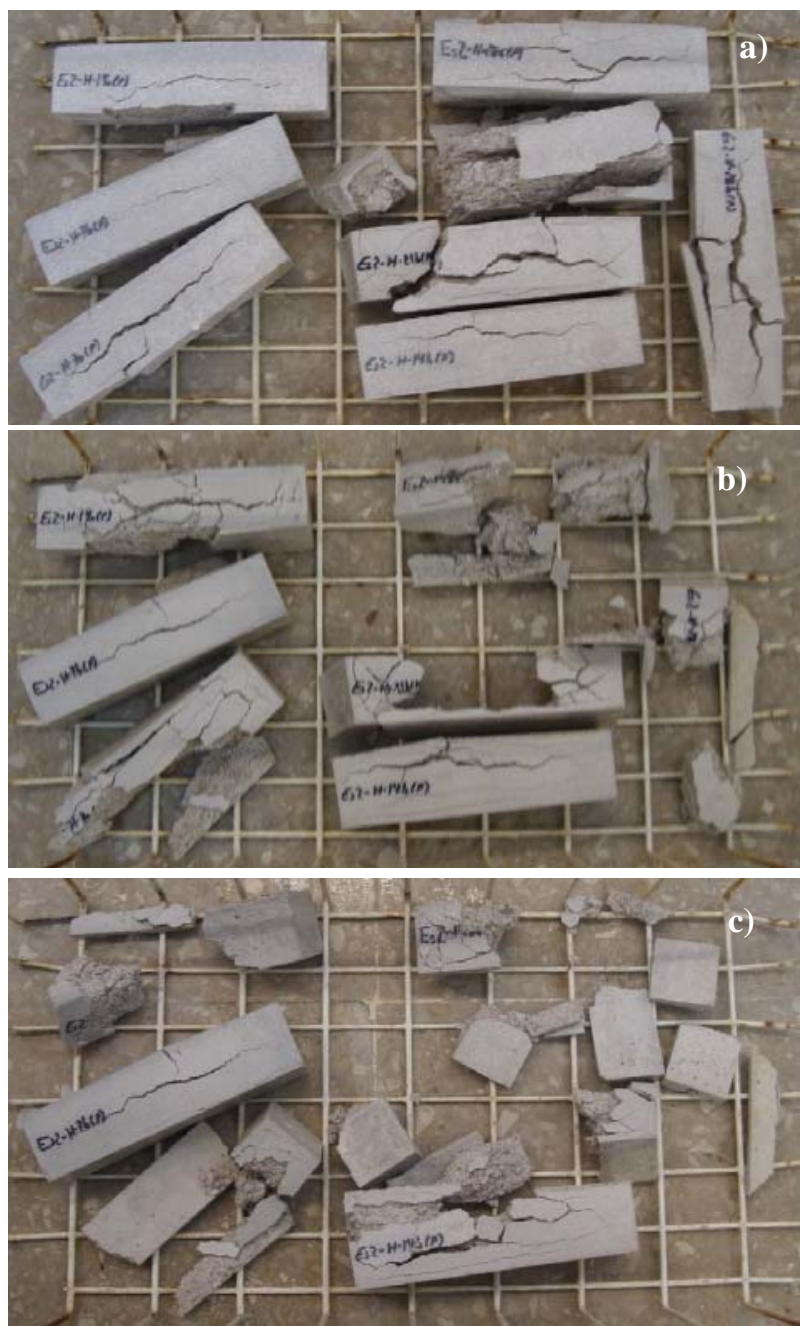

Fig. 5. Evolution of aerial lime-based mortars after: a) 1 freezing-thawing cycle; b) 2 cycles; c) 3 cycles. 


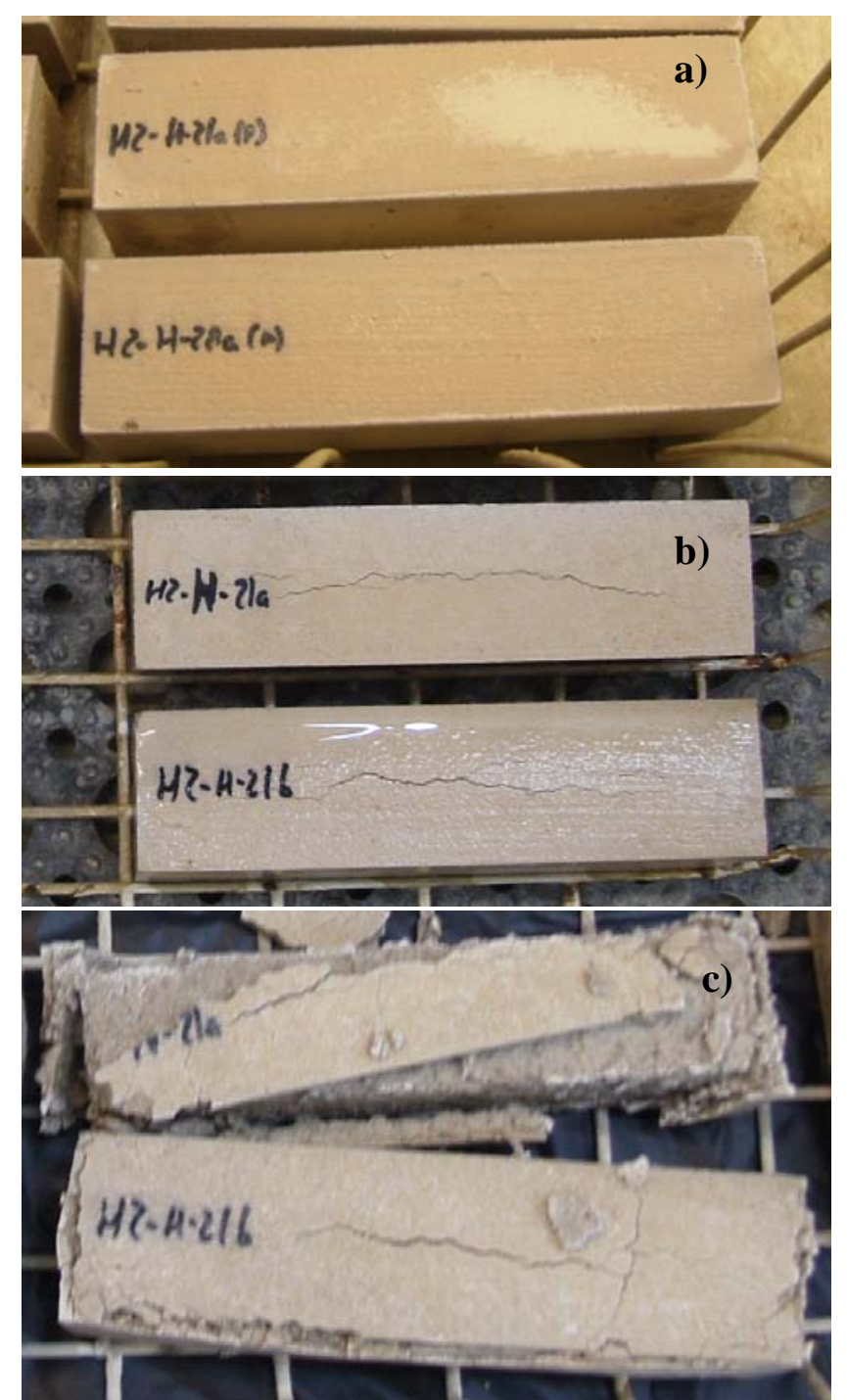

Fig. 6. Evolution of hydraulic lime-based mortars after: a) 1 freezing-thawing cycle; b) 3 cycles; c) 11 cycles.

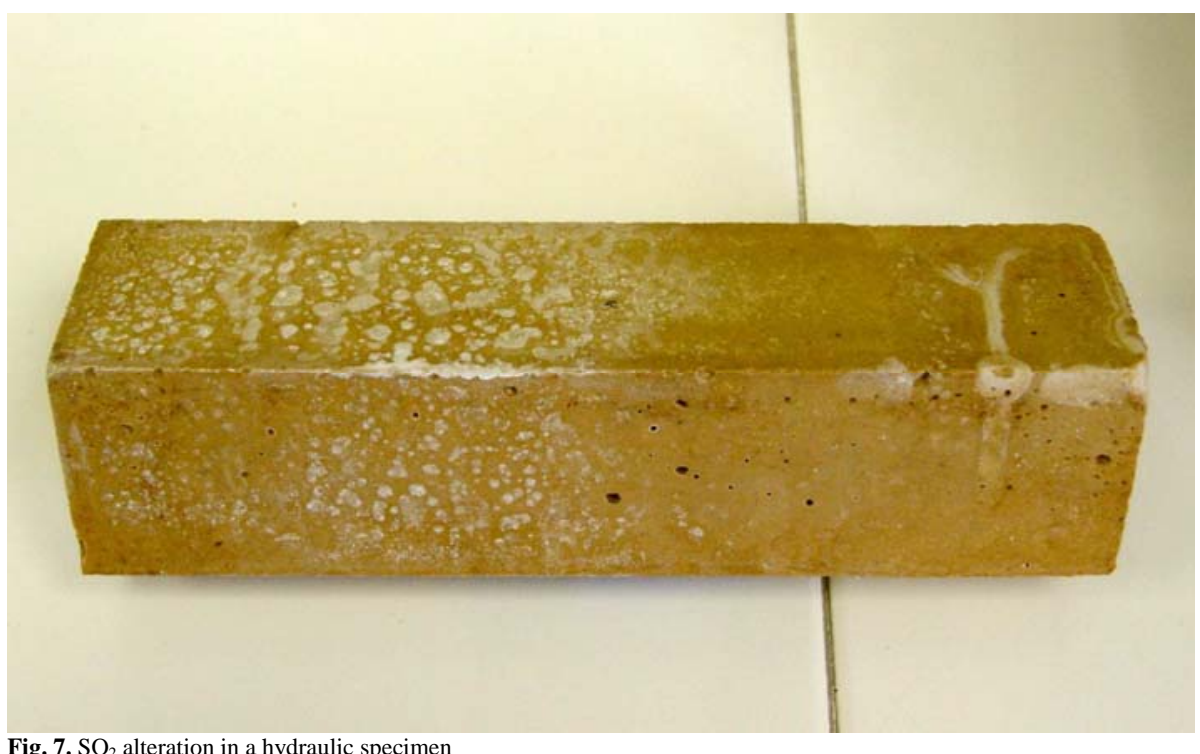

Fig. 7. $\mathrm{SO}_{2}$ alteration in a hydraulic specimen 


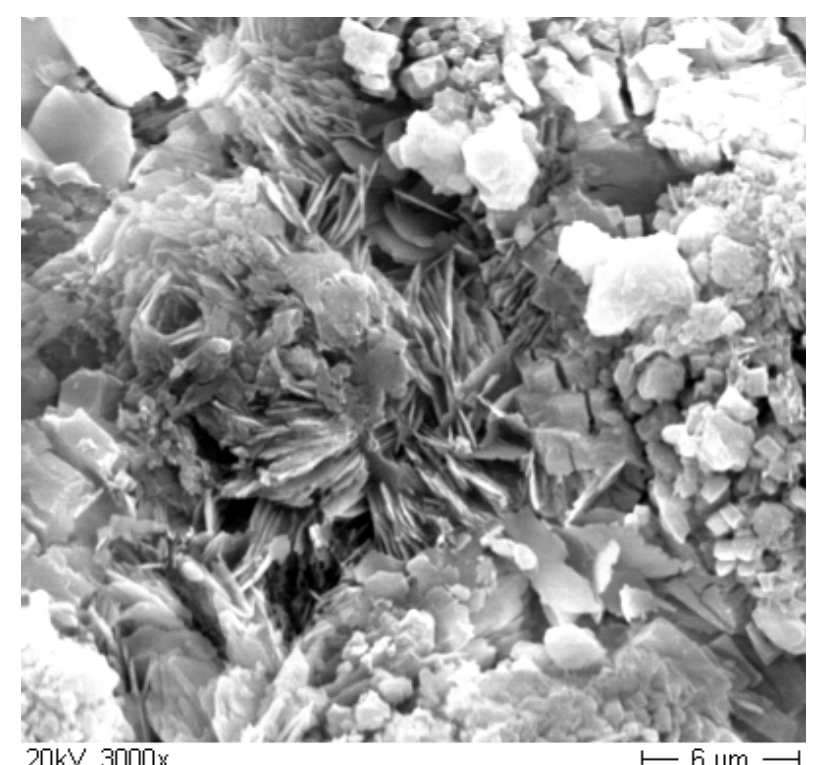

Fig. 8. Micrograph showing plate-like gypsum crystals. Aerial lime based mortar.

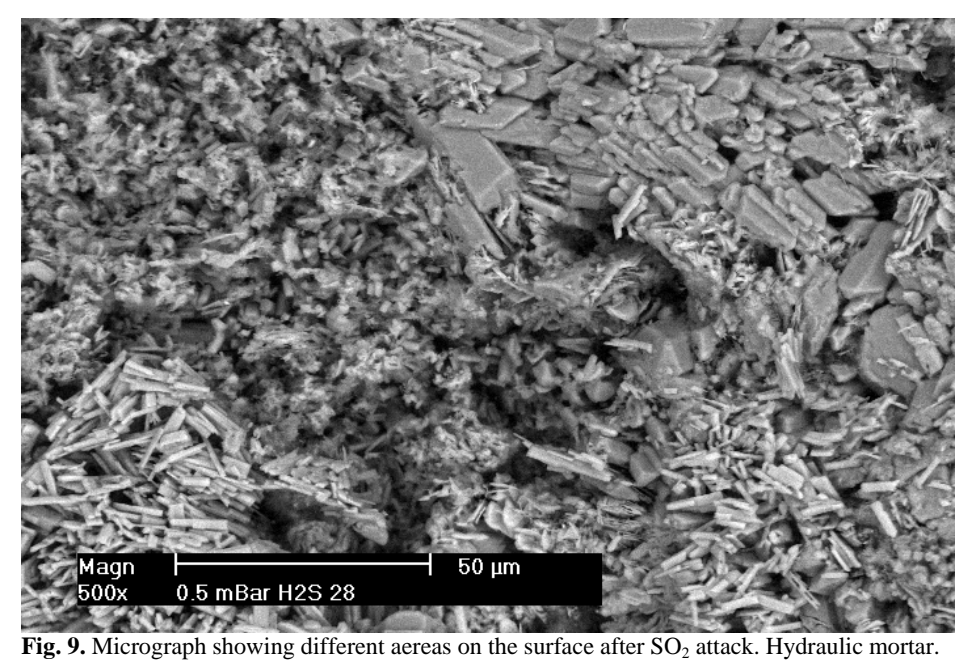

Fig. 9. Micrograph showing different aereas on the surface after $\mathrm{SO}_{2}$ attack. Hydraulic mortar.

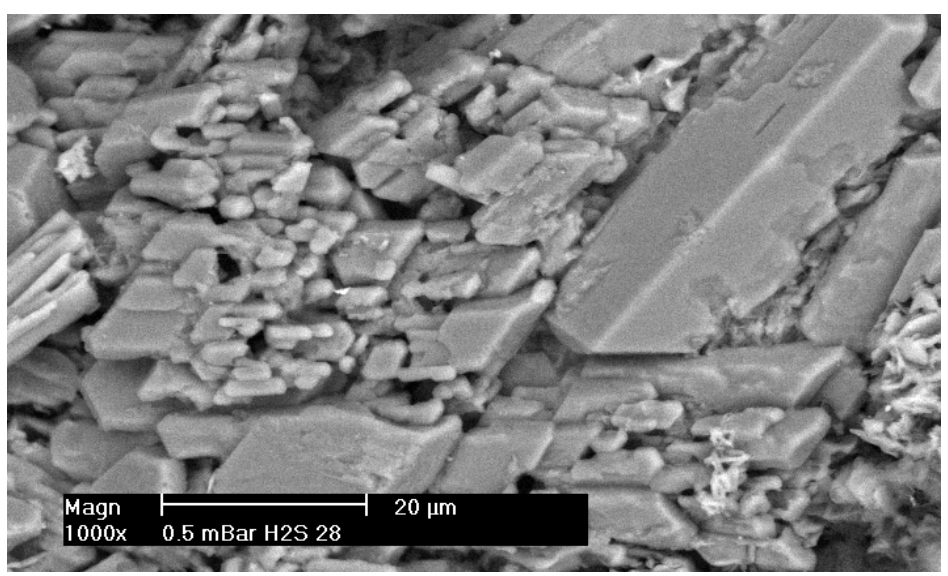

Fig. 10 (a). Magnification of large prysmatic gypsum crystals. Hydraulic mortar. 


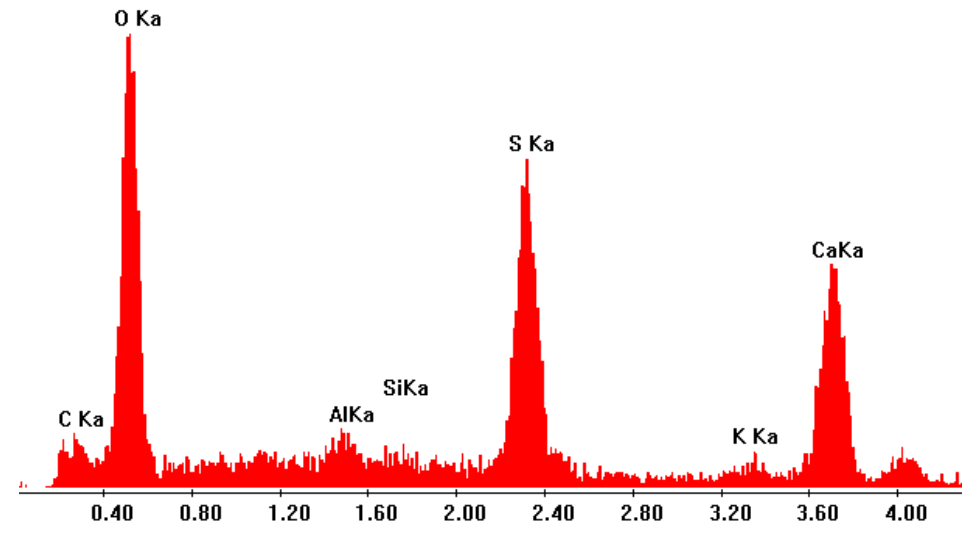

Fig. 10(b). EDAX result showing the $\mathrm{Ca}, \mathrm{S}$ and $\mathrm{O}$ presence.

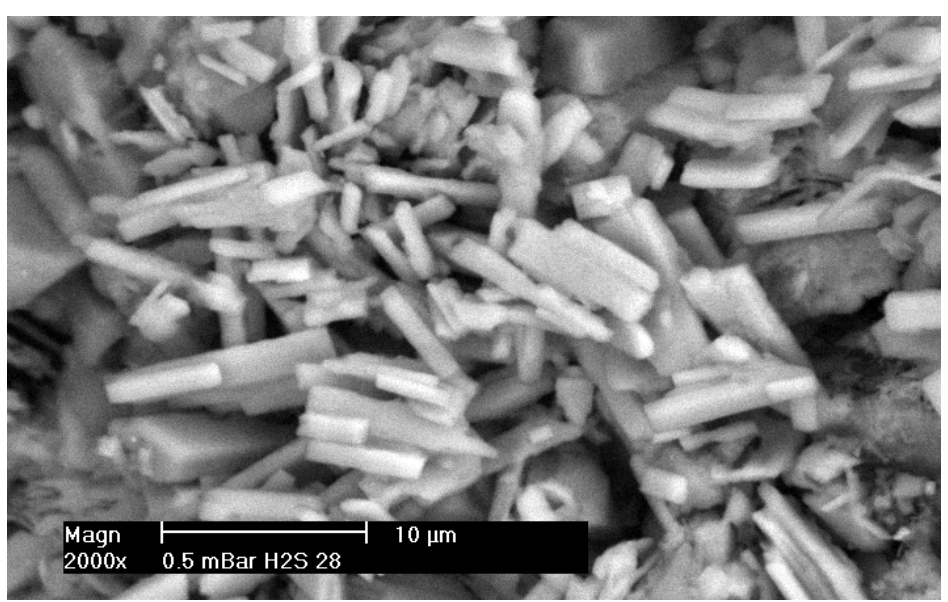

Fig. 11(a). Magnification showing syngenite needle-shaped crystals. Hydraulic mortar.

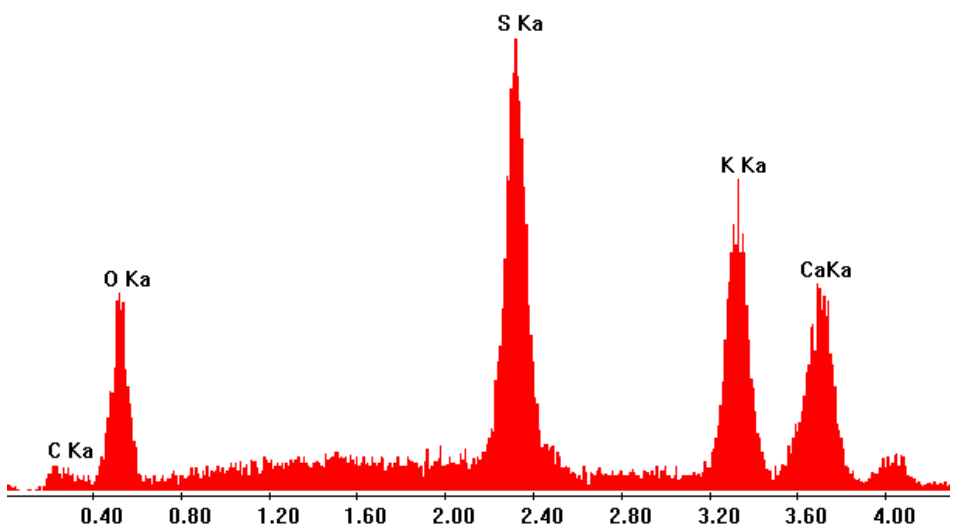

Fig. 11(b). EDAX result showing $C a, K, S$ and $O$ presence. 


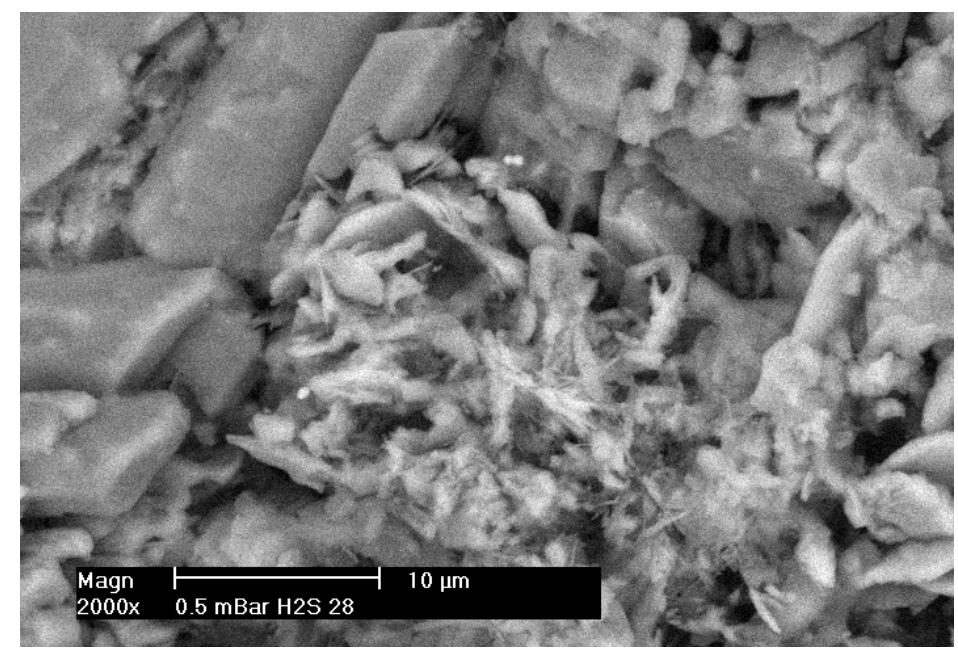

Fig. 12(a). Micrograph showing CSH crystals close to gypsum crystals. Hydraulic specimen.



Fig. 12(b). EDAX result showing $\mathrm{S}, \mathrm{O}$ and Ca presence (corresponding to gypsum crystals), as well as $\mathrm{Si}$ and $\mathrm{Al}$, attributed to CSH gel.

Table 1. Chemical analysis of the aerial, natural hydraulic lime and aggregate ${ }^{\mathrm{a}, \mathrm{b}}$.

\begin{tabular}{|c|c|c|c|c|c|c|c|c|}
\hline $\begin{array}{c}\text { Raw } \\
\text { material }\end{array}$ & $\begin{array}{l}\text { I. L. }{ }^{c} \\
(\%)\end{array}$ & $\begin{array}{l}\mathrm{SiO}_{2} \\
(\%)\end{array}$ & $\begin{array}{l}\mathrm{CaO} \\
(\%)\end{array}$ & $\begin{array}{l}\text { MgO } \\
(\%)\end{array}$ & $\begin{array}{c}\mathrm{R}_{2} \mathrm{O}_{3}{ }^{\mathrm{d}} \\
(\%)\end{array}$ & $\begin{array}{l}\mathrm{SO}_{3} \\
(\%)\end{array}$ & $\begin{array}{c}\mathrm{Na}_{2} \mathrm{O} \\
(\%)\end{array}$ & $\begin{array}{l}\mathrm{K}_{2} \mathrm{O} \\
(\%)\end{array}$ \\
\hline $\begin{array}{l}\text { Aerial lime } \\
\text { (Estavol ®) }\end{array}$ & 25.46 & 0.71 & 68.26 & 3.55 & 0.55 & 0.96 & 0.07 & 0.04 \\
\hline $\begin{array}{l}\text { Natural } \\
\text { hydraulic } \\
\text { lime }\end{array}$ & 15.00 & 12.57 & 54.26 & 7.65 & 6.58 & 2.13 & 0.34 & 1.35 \\
\hline $\begin{array}{l}\text { Aggregate } \\
\text { (Ag) }\end{array}$ & 43.10 & 0.49 & 52.83 & 2.28 & 1.14 & 0.57 & 0.07 & 0.05 \\
\hline
\end{tabular}

${ }^{a}$ Percentages related to original dry sample.

${ }^{\mathrm{b}}$ The methods specified by the European Standard EN-196 were followed for the chemical analyses.

${ }^{\mathrm{c}}$ Ignition loss, indicates the weight loss due to calcination at $975-1000{ }^{\circ} \mathrm{C}$

${ }^{\mathrm{d}}$ Percentage of $\mathrm{Fe}$ and $\mathrm{Al}$ oxides together. 
Table 2. Equivalencies volume proportion/weight proportion for aerial and hydraulic lime-based mortars.

\begin{tabular}{|c|c|c|c|c|c|}
\hline $\begin{array}{c}\text { Lime-based } \\
\text { mortar }\end{array}$ & $\begin{array}{c}\text { Volume } \\
\text { proportion }\end{array}$ & Material & $\begin{array}{c}\text { Volume } \\
\text { (L) }\end{array}$ & $\begin{array}{c}\text { Weight } \\
\text { (g) }\end{array}$ & $\begin{array}{c}\text { Weight } \\
\text { proportion }\end{array}$ \\
\hline Aerial & $1: 1$ & $\begin{array}{c}\text { Lime } \\
\text { Aggregate }\end{array}$ & $\begin{array}{l}2.00 \\
2.00\end{array}$ & $\begin{array}{c}800 \\
3000\end{array}$ & 1:3.75 \\
\hline Hydraulic & $1: 1$ & $\begin{array}{c}\text { Lime } \\
\text { Aggregate }\end{array}$ & $\begin{array}{l}2.00 \\
2.00\end{array}$ & $\begin{array}{l}1400 \\
3000\end{array}$ & $1: 2.14$ \\
\hline
\end{tabular}

Table 3. Steps of the climatic chamber.

\begin{tabular}{lccccc}
\hline $\begin{array}{c}\text { Cycle } \\
(\mathbf{2 4} \mathbf{~ h})\end{array}$ & $\begin{array}{c}\text { Temperature } \\
\mathbf{( { } ^ { \circ } \mathbf { C } )}\end{array}$ & $\begin{array}{c}\mathbf{R . ~ H}^{\mathbf{a}} \\
\mathbf{( \% )}\end{array}$ & Rain & Light & $\begin{array}{c}\text { Time } \\
(\mathbf{m i n})\end{array}$ \\
\hline Step 1 & 35 & 30 & no & yes & 160 \\
Step 2 & 12 & 60 & yes & no & 160 \\
Step 3 & -5 & 0 & no & no & 160 \\
Step 4 & 12 & 60 & no & no & 160 \\
Step 5 & 35 & 30 & no & yes & 160 \\
Step 6 & 12 & 80 & yes & no & 160 \\
Step 7 & 35 & 30 & no & yes & 160 \\
Step 8 & -5 & 0 & no & no & 160 \\
Step 9 & 12 & 60 & no & no & 160 \\
${ }^{\text {a }}$ Relative humidity & & & & &
\end{tabular}

Table 4. $\mathrm{SO}_{2}$-chamber cycles.

\begin{tabular}{|c|c|c|c|c|c|c|}
\hline $\begin{array}{c}\begin{array}{c}\text { Cycle } \\
\text { duration }\end{array} \\
\end{array}$ & $\begin{array}{c}\mathrm{SO}_{2} \\
\text { addition } \\
(\mathrm{L})\end{array}$ & $\begin{array}{c}\mathrm{H}_{2} \mathrm{O} \\
\text { addition } \\
(\mathrm{L}) \\
\end{array}$ & Steps & $\begin{array}{c}\mathbf{T} \\
\left({ }^{\circ} \mathrm{C}\right)\end{array}$ & $\begin{array}{c}\text { R. H. } \\
(\%)\end{array}$ & $\begin{array}{c}\text { Time } \\
\text { (h) }\end{array}$ \\
\hline \multirow[b]{2}{*}{$24 \mathrm{~h}$} & \multirow[b]{2}{*}{2} & \multirow[b]{2}{*}{$2 \pm 0.2$} & step 1 & $40 \pm 3$ & 100 & 8 \\
\hline & & & step 2 & $\begin{array}{c}\text { Room } \\
\text { temperature }\end{array}$ & $<75$ & 16 \\
\hline
\end{tabular}

Table 5. Freezing-thawing test cycles.

\begin{tabular}{|c|c|c|c|c|}
\hline $\begin{array}{c}\text { Cycle } \\
\text { Duration }\end{array}$ & Steps & $\begin{array}{c}\text { Temperature } \\
\left({ }^{\circ} \mathrm{C}\right)\end{array}$ & $\begin{array}{c}\text { Water } \\
\text { immersion }\end{array}$ & Time \\
\hline \multirow{2}{*}{ Indefinite } & Step 1 & $\begin{array}{c}\text { Room } \\
\text { temperature }\end{array}$ & Yes & \multirow{2}{*}{$\begin{array}{l}\text { Until the specimens are } \\
\text { completely saturated } \\
\text { Until the specimens are } \\
\text { completely frozen }\end{array}$} \\
\hline & Step 2 & $-10 \pm 2$ & No & \\
\hline
\end{tabular}


Table 6. Qualitative evaluation of the alteration degree in climatic chamber: percentages of specimens in the different alteration degrees.

\begin{tabular}{|c|c|c|c|c|c|c|c|c|c|c|c|c|}
\hline \multirow[b]{3}{*}{ Cycles } & \multicolumn{12}{|c|}{ Alteration degrees } \\
\hline & \multicolumn{6}{|c|}{ Aerial lime-based mortars } & \multicolumn{6}{|c|}{ Hydraulic lime-based mortars } \\
\hline & $\mathbf{0}$ & 1 & 2 & 3 & 4 & 5 & $\mathbf{0}$ & 1 & 2 & 3 & 4 & 5 \\
\hline 0 & 100 & 0 & 0 & 0 & 0 & 0 & 100 & 0 & 0 & 0 & 0 & 0 \\
\hline 7 & 0 & 0 & 0 & 0 & 0 & 100 & 76.5 & 23.5 & 0 & 0 & 0 & 0 \\
\hline 14 & 0 & 0 & 0 & 0 & 0 & 100 & 8.3 & 16.7 & 41.7 & 33.3 & 0 & 0 \\
\hline 21 & 0 & 0 & 0 & 0 & 0 & 100 & 0 & 0 & 50 & 50 & 0 & 0 \\
\hline 28 & 0 & 0 & 0 & 0 & 0 & 100 & 0 & 0 & 0 & 66.7 & 33.3 & 0 \\
\hline
\end{tabular}

Equivalencies of the alteration degrees:

0 : Without alteration,

1: Slightly altered, some small (thin and short) cracks at the surface of the specimens.

2: Altered, several cracks (like spider's web) and more deep.

3: Very altered, several deep cracks and swelling of the specimen.

4: High degree of alteration, large and deep cracks, large swelling of the specimen including a partial weight loss.

5: Completely altered, the specimen is practically destroyed, only are kept little pieces of them.

Table 7. Qualitative evaluation of the alteration degree in freezing-thawing cycles: percentages of specimens in the different alteration degrees.

Alteration degrees

\begin{tabular}{|c|c|c|c|c|c|c|c|c|c|c|c|c|}
\hline \multirow[b]{2}{*}{ Cycles } & \multicolumn{6}{|c|}{ Aerial lime-based mortars } & \multicolumn{6}{|c|}{ Hydraulic lime-based mortars } \\
\hline & $\mathbf{0}$ & 1 & 2 & 3 & 4 & 5 & $\mathbf{0}$ & 1 & 2 & 3 & 4 & 5 \\
\hline 0 & 100 & 0 & 0 & 0 & 0 & 0 & 100 & 0 & 0 & 0 & 0 & 0 \\
\hline 2 & 0 & 23.8 & 19 & 28.6 & 28.6 & 0 & 64.7 & 35.3 & 0 & 0 & 0 & 0 \\
\hline 3 & 0 & 0 & 0 & 0 & 0 & 100 & 20 & 26.7 & 53.3 & 0 & 0 & 0 \\
\hline 4 & 0 & 0 & 0 & 0 & 0 & 100 & 16.7 & 22.1 & 44.4 & 16.7 & 0 & 0 \\
\hline 7 & 0 & 0 & 0 & 0 & 0 & 100 & 0 & 15.4 & 15.4 & 69.2 & 0 & 0 \\
\hline 9 & 0 & 0 & 0 & 0 & 0 & 100 & 0 & 8.3 & 16.7 & 75.0 & 0 & 0 \\
\hline 11 & 0 & 0 & 0 & 0 & 0 & 100 & 0 & 11.1 & 11.1 & 22.2 & 55.6 & 0 \\
\hline
\end{tabular}

Equivalencies of the alteration degrees:

0 : Without alteration,

1: Slightly altered, some small (thin and short) cracks at the surface of the specimens.

2: Altered, several cracks (like spider's web) and more deep.

3: Very altered, several deep cracks and swelling of the specimen.

4: High degree of alteration, large and deep cracks, large swelling of the specimen including a partial weight loss.

5: Completely altered, the specimen is practically destroyed, only are kept little pieces of them.

Table 8. Open porosity values of hardened pastes

\begin{tabular}{|c|c|c|c|c|c|c|c|c|}
\hline \multirow[b]{3}{*}{$\begin{array}{l}\text { Test } \\
\text { day }\end{array}$} & \multicolumn{8}{|c|}{ Porosity (\%) } \\
\hline & \multicolumn{4}{|c|}{ Aerial lime-based mortars } & \multicolumn{4}{|c|}{ Hydraulic lime-based mortars } \\
\hline & Outside & Climatic & Indoor & $\mathrm{SO}_{2}$ & Outside & Climatic & Indoor & $\mathrm{SO}_{2}$ \\
\hline 0 & \multicolumn{4}{|c|}{$\leftarrow 33.80 \rightarrow$} & \multicolumn{4}{|c|}{$\leftarrow 31.77 \rightarrow$} \\
\hline 7 & 34.29 & - & 33.80 & 33.32 & 32.04 & 32.64 & 32.08 & 31.41 \\
\hline 14 & 33.33 & - & 33.64 & 33.50 & 30.52 & 32.44 & 31.13 & 30.04 \\
\hline 21 & 33.65 & - & 33.75 & 33.92 & 30.62 & 33.00 & 31.70 & 30.20 \\
\hline 28 & 33.75 & - & 34.26 & 33.75 & 30.54 & 33.15 & 31.63 & 28.78 \\
\hline
\end{tabular}

